\title{
Increased medial tibial slope in teenage pediatric population with open physes and anterior cruciate ligament injuries
}

\author{
Shail Vyas • Carola F. van Eck • Nina Vyas • \\ Freddie H. Fu • Norman Y. Otsuka
}

Received: 12 May 2010/Accepted: 29 June 2010/Published online: 30 July 2010

(C) The Author(s) 2010. This article is published with open access at Springerlink.com

\begin{abstract}
Purpose Variations in bony morphology have been associated with anterior cruciate ligament (ACL) injury risk. The primary aim of this study was to compare the tibial slope in the teenage pediatric population with open physes, with and without ACL injury. The secondary aims were to compare the notch width index (NWI) and determine the influence of gender and age on tibial slope and NWI.

Methods Thirty-nine teenage pediatric subjects were included in this study, 16 with and 23 without ACL injury. Medial tibial slope and lateral tibial slope and NWI as measured on plain radiographs were compared between the groups using an independent $t$-test. Comparison of tibial slope and NWI was also performed between male and female subjects. Pearson correlation coefficient between age and tibial slope and NWI was calculated.

Results The medial tibial slope averaged $10.2( \pm 3.9)$ degrees, the lateral tibial slope $11.5( \pm 3.9)$ degrees, and the NWI 0.26. There was a significant difference in medial
\end{abstract}

S. Vyas

Department of Orthopedic Surgery, University of California Los Angeles, 10833 Le Conte Ave, Los Angeles, CA 90095, USA

S. Vyas - C. F. van Eck - F. H. Fu

University of Pittsburgh, Kaufman Building Suite 1011,

3471 Fifth Avenue, Pittsburgh, PA 15213, USA

N. Vyas

University of California San Diego, 9500 Gilman Dr.,

La Jolla, CA 92093, USA

N. Y. Otsuka $(\square)$

Shriners Hospitals for Children Los Angeles, 3160 Geneva St., Los Angeles, CA 90020, USA

e-mail: notsuka@shrinenet.org tibial slope between the ACL-injured (12.1 degrees) subjects and the controls ( 8.9 degrees $)(P=0.009)$. There was no significant difference in lateral tibial slope or NWI between the groups. There was no significant difference in the medial tibial slope and lateral tibial slope and NWI between the male and female subjects. Subject age was not correlated with medial tibial slope and lateral tibial slope or NWI.

Conclusion There was an increased medial tibial slope in ACL-injured teenagers with open physes, when compared to a control group of teenager with open physes without ACL injury.

Keywords Posterior tibial slope $\cdot$ Notch width index · Anterior cruciate ligament - ACL - Open physes . Pediatric

\section{Introduction}

Variations in bony morphology have long been thought to be associated with anterior cruciate ligament (ACL) injury risk $[13,14,18,26]$. On the femoral side, small intercondylar notch dimensions have been correlated with an increased risk of ACL rupture [26]. Similarly, tibial bony anatomy may have an effect on the ACL. The slope of the proximal tibia averages approximately 10 degrees with a variation of 3 degrees in the adult literature [7, 11, 12]. An increase in tibial slope may predispose to ACL rupture. Bony morphology may especially play a role in ACL injuries in children [9]. However, the relationship between tibial slope and ACL injury in this population has not been studied. The primary aim of this study is to compare the tibial slope in the teenage pediatric subjects with open physes with and without ACL injury. We hypothesized an 
increased tibial slope in the subjects with ACL injury. The secondary aims were to compare the notch width index (NWI) between pediatrics subjects with open physes with and without ACL injury; to evaluate the influence of gender and age on tibial slope and NWI; and to evaluate the reliability of measuring tibial slope and NWI on plain radiographs in pediatric subjects.

\section{Materials and methods}

Between January 2002 and January 2009, all teenage pediatric subjects undergoing ACL reconstruction were included in this study. Inclusion criteria were open physes, lateral and anterior-posterior radiographs of the knee of good quality, presence of an ACL tear as appreciated on magnetic resonance imaging (MRI), and/ or observed during surgery. Subjects with closed physes and evidence of knee morphological abnormalities were excluded. A control group was retrospectively selected from teenage pediatric subjects with open physes of similar age and gender with anterior-posterior and lateral radiographs of the knee of good quality, without presence of an ACL tear as confirmed on MRI. Retrospective selection of the control group was essential to ensure subjects did not suffer an ACL injury before their physes were closed. Subjects with closed physes were excluded.

From the included subjects, lateral and anterior-posterior radiographs of the knee were collected, and their age and gender were recorded. Two independent blinded observers measured the medial tibial slope and lateral tibial slope on the lateral radiographs, using the technique by Brandon et al. [3]. This technique considers the posterior tibial slope as 90 degrees subtracted by the angle formed by the tibial plateau and the longitudinal axis of the tibia. This longitudinal axis has been described as the line formed by two points along the proximal aspect of the tibia. The first point is at the midpoint between anterior and posterior cortex at the level of the tibial tubercle, and the second point is at the same midpoint five centimeters distal to the tubercle. The line joining these points describes the longitudinal axis of the tibia (Fig. 1). The tibial slope was determined on both the medial side (medial tibial slope) and the lateral side (lateral tibial slope). Measurement of tibial slope on radiographs has been shown to have an accuracy of approximately one degree [11]. Two independent observers subsequently measured the NWI on the anterior-posterior radiographs, according to the method by Souryal et al. [27]. The observers were blinded to the subjects' medical history. Institutional review board approval was obtained for this study.

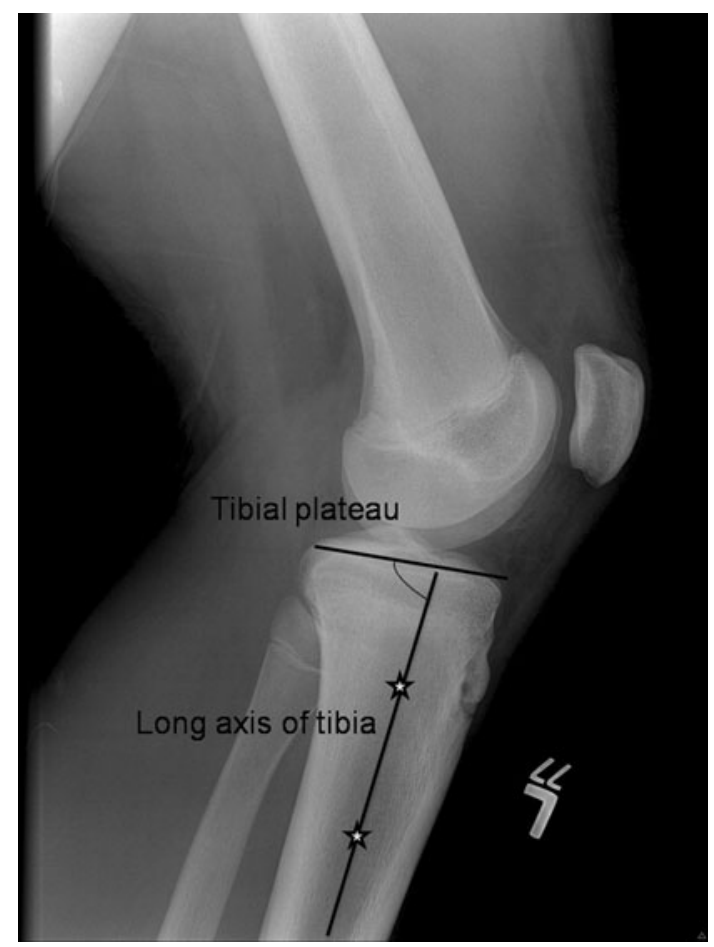

Fig. 1 The medial tibial slope is determined by subtracting the angle shown in the above figure from 90 degrees. The long axis of the tibia is determined drawing a line defined by two points; one midway between the anterior and posterior border of the tibia at the level of the tibial tubercle and the other $5 \mathrm{~cm}$ distal to the tubercle

Statistical analysis

The data were analyzed with PASW Statistics (version 17.0, SPSS Inc., Chicago, IL). The measurements of the first observer were used for statistical analysis of the results. The ratio, mean, range, and standard deviation of the gender and age of all included subjects were calculated. An independent $t$-test was performed to assess whether the ACL-injured and control group had comparative baseline characteristics. An independent $t$-test was also used to determine the difference in medial tibial slope, lateral tibial slope, and NWI between male and female subjects and between ACL-injured and control subjects. The Pearson correlation coefficient was calculated to determine the correlation between the medial tibial slope, lateral tibial slope, and NWI; and subject age. The a priori alpha level for statistical significance was set at $P<0.05$. Lastly, the intra-class correlation coefficient (ICC) was calculated to determine inter-observer reliability for the medial tibial slope, lateral tibial slope, and NWI. Before conducting this study, a sample size calculation was performed. An average PTS of 10 degrees was assumed, and a difference equal to or exceeding the variation reported in literature (3 degrees) was thought to be clinically relevant. This sample size analysis revealed that a total of 16 subjects were 
needed in both the ACL-injured and the control group to obtain a power of $80 \%$.

\section{Results}

Thirty-nine subjects were included in this study, 16 with and 23 without ACL injury. Fifty-five percent were men and $45 \%$ women, with an average age of 15 year (189 months), ranging from 12 to 17 years (151-215 months). There was a baseline difference in age between the ACL-injured and the control group, with a higher age in the ACL-injured group (196 vs. 173 months, respectively, $P=0.02$ ).

The mean, range, and standard deviation of the medial tibial slope and lateral tibial slope and notch width index are displayed in Table 1 (Fig. 2). The medial tibial slope among all 39 subjects averaged 10.2 degrees and the lateral tibial slope 11.5 degrees. There was a significant difference in medial tibial slope between the ACL-injured subjects and the controls $(P=0.009)$. The average medial tibial slope of the ACL-injured subjects was 12.1 degrees (standard deviation 3.3 degrees), whereas it averaged 8.9 degrees (standard deviation 3.8 degrees) for the control group. There was no significant difference in lateral tibial slope or NWI between the groups. There was no significant difference in the medial tibial slope and lateral tibial slope and NWI between the male and female subjects. Subject age was not correlated with medial tibial slope and lateral tibial slope of NWI.

The intra-class correlation coefficient for the medial tibial slope, lateral tibial slope, and NWI were 0.962, 0.972 , and 0.958 , respectively. The corresponding $95 \%$ confidence intervals are displayed in Table 2.

\section{Discussion}

The most important finding of the present study was that there is a significantly increased medial tibial slope in teenaged pediatric subjects with open physes with ACL injuries, when compared to subjects with open physes without ACL injury. These results correspond with existing research involving the adult population [3]. The primary

Table 1 Tibial slope and notch measurements of the 39 included subjects

\begin{tabular}{lllll}
\hline & Mean & SD & Min & Max \\
\hline Medial tibial slope $\left(^{\circ}\right)$ & 10 & 3.9 & 0 & 19 \\
Lateral tibial slope $\left(^{\circ}\right)$ & 11 & 3.9 & 2 & 20 \\
NWI & 0.26 & 0.05 & 0.13 & 0.37 \\
\hline
\end{tabular}

$N W I$ Notch width index, $S D$ Standard deviation, Min Minimal value, Max Maximal value

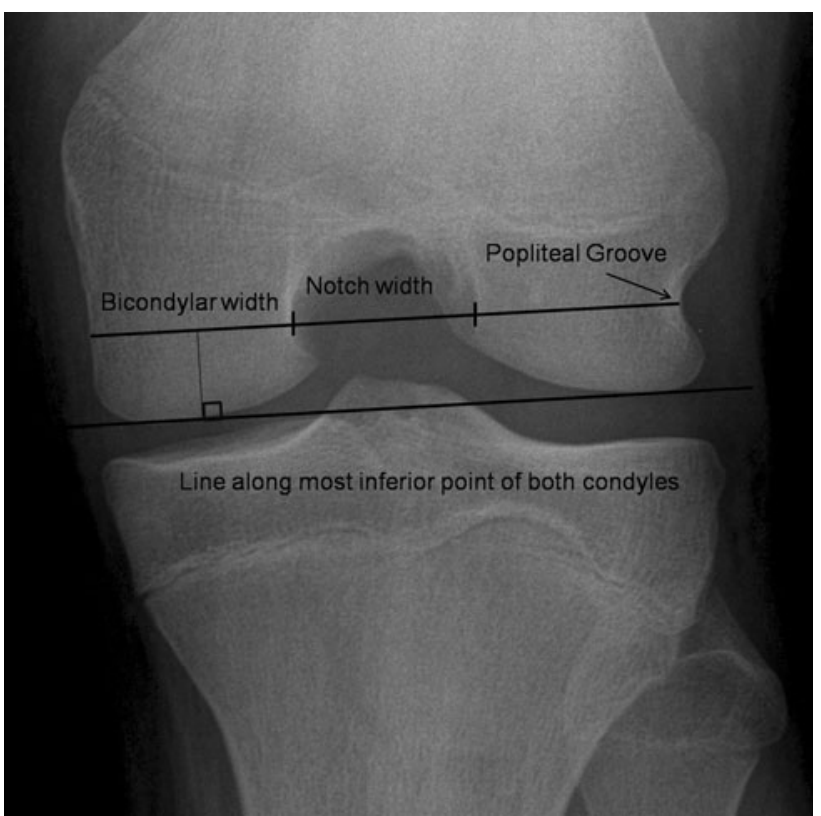

Fig. 2 Method to measure the notch width index. A line is drawn between the most inferior points of both condyles. The bicondylar width is measured along this line, at the level of the popliteal groove. Lastly, the notch width is measured at this same level

Table 2 Inter-class correlation coefficient of the medial tibial slope, lateral tibial slope, and NWI, as measured on plain radiographs

\begin{tabular}{ll}
\hline Medial tibial slope & $0.962(0.827-0.990)$ \\
Lateral tibial slope & $0.972(0.903-0.992)$ \\
Notch width index (NWI) & $0.958(0.847-0.989)$
\end{tabular}

95\% CI 95\% confidence interval

aim of this study was to determine whether there was relationship between the tibial slope and ACL injury. The hypothesis was that an increased tibial slope is associated with ACL injury in the teenage population, which was affirmed. This association may be based on the biomechanical changes associated with a change in the knee bony morphology. Dejour et al. [7] showed every 10 degree increase in posterior inclination of the tibial plateau was associated with a 6-mm increase in anterior tibial translation and a $3-\mathrm{mm}$ increase in the Lachman test. The results of this prospective clinical study were confirmed by a controlled laboratory study in which cadaveric knee underwent osteotomy to simulate an increase in tibial slope [12]. The authors found this moved the resting position of the tibia on average $3.6 \mathrm{~mm}$ more anterior with respect to the femur [12]. The increase in anterior-posterior translation in the knee, caused by the increased tibial slope, may predispose the teenage population in our study to ACL injuries. Indeed, Giffin et al. [12] recommended in their paper that ACL-deficient subjects may benefit from a reverse osteotomy, decreasing the tibial slope. The findings 
of the present study and previous studies are important to serve as a basis for more sophisticated biomechanical studies to assess the strain on the ACL with simulated weight bearing in varying degrees of posterior slope. Subjects with an increased tibial slope who are participating in high-risk activities should perhaps consider prophylactic precautions. This could include education on the increased risk for ACL rupture, as well as injury prevention training.

The current study showed no significant difference in lateral tibial slope between the ACL-injured and control group. This was different from the results of a similar studies in adults, which found an increase in lateral tibial slope in ACL-injured subjects, compared to controls $[25,28]$. That the present study found a difference in medial, but not in lateral tibial slope, could be because the medial tibial slope has a closer approximation to the tibial AM bundle insertion site, therefore increasing its influence on anterior-posterior translation, when compared to the lateral tibial slope $[5,10,33]$. The average tibial slope was similar to previous studies in adult literature $[7,11,12]$. In addition to what has been described in existing literature, the present study measured the tibial slope for both the medial and the lateral side.

One of the secondary aims was to compare the NWI between teenage pediatrics subjects with and without ACL injury. This study showed no significant difference between the ACL-injured and control group. The femoral intercondylar notch has long been thought to be associated with ACL rupture risk. Chondrocytes have been found on the ACL surface, showing contact between the ACL and the notch $[23,24]$. Multiple studies in the adult literature demonstrate a relationship between certain notch dimensions and the incidence of ACL rupture [2, 15, 17-19, 21, 26], while other studies do not show a relationship [16, 20]. NWI is one of the most frequently used methods to measure notch size. However, although it has been shown to be highly reliable [31], it may not be very accurate [1], possibly accounting for the discrepancy of results in existing literature. Furthermore, it has been shown that the NWI does not correlate with the overall notch volume [31]. Other dimensions than just the notch outlet, such as notch volume and notch shape [32], may be associated with ACL injury risk, requiring three-dimensional evaluation.

This study also aimed to evaluate the influence of age on the tibial and femoral bony morphology. There was no correlation between age and medial tibial slope or lateral tibial slope and NWI. This was as expected, as it was hypothesized that these variations in bony morphology are congenital rather than developed, therefore predisposing to ACL injury. There was no significant difference in the medial tibial slope, lateral tibial slope, and NWI between male and female subjects. We hypothesized there may be a difference in bony morphology between genders, since it has been shown by multiple studies that women have a greater propensity for ACL injury compared to their male counterparts $[4,6,8,22,30]$. It has been suggested that a possible risk factor for this observation is that women have a narrower notch than men and even smaller ACLs [4, 29, 32]. However, the present study did not demonstrate such a difference for the studied teenage pediatric population with open physes.

The last aim was to test the reliability of measuring medial tibial slope, lateral tibial slope, and NWI on lateral and anterior-posterior plain radiographs of the knee. The intra-class correlation coefficient for inter-observer reliability for all measurements was well above 0.9 , proving the methods highly reliable. This validated using the measurements of the first observer for statistical analysis of the data.

Limitations of the present study mostly involve those associated with measurements on plain radiographs described earlier. Although our measurements of tibial slope and notch width proved highly reliable, accuracy may be influenced by slight variation in rotation and angulation [1, 18]. Sample size calculation before the start of this study determined a total of 32 subjects would be sufficient to show statistically significant results. Our study included 39 subjects. We aimed to include more subjects, which was not possible due to our high demands for the quality of the radiographs in combination with the lower number of ACL ruptures in the pediatric population when compared to the adult population. Another limitation was that there was a baseline difference in age between the ACL-injured and the control group, with the control group being slightly older. However, our study showed no correlation between age and the various measured parameters of bony morphology. It needs to be noted that the precise age of some of the subjects was unknown and therefore the aforementioned correlation calculation only involved those subjects whose precise age (in months) was known. The control group was a group of subjects who had undergone radiographs and an MRI of the knee for various "knee pain" reasons and other than ACL injury. They were not a homogenous group with a single diagnosis nor were they the perfect control group, composed of healthy subjects on whom radiographs were deliberately taken for control purposes. The latter was not sought for patient safely purposes in attempt to avoid radiation exposure in the growing pediatric subjects. Lastly, this study assessed subjects retrospectively that had suffered an ACL injury during their teenage years in which their physes were still open, and control subject of whom it was validated they did not suffer an ACL injury in this time frame. However, this last group may still go on to injure their ACL in subsequent years. 


\section{Conclusion}

In conclusion, the present study aimed to compare tibial slope between teenage subjects with open physes with ACL injury and those without ACL injury. There was a significantly higher medial tibial slope in ACL-injured subjects. There was no difference in lateral tibial slope, or NWI. Age was not correlated with tibial slope or NWI and neither was gender. Measuring medial tibial slope and lateral tibial slope on lateral radiographs and NWI on anterior-posterior radiographs proved highly reliable.

Acknowledgments The authors did not receive any outside funding or grants directly related to the research presented in this manuscript.

Open Access This article is distributed under the terms of the Creative Commons Attribution Noncommercial License which permits any noncommercial use, distribution, and reproduction in any medium, provided the original author(s) and source are credited.

\section{References}

1. Anderson AF, Anderson CN, Gorman TM, Cross MB, Spindler KP (2007) Radiographic measurements of the intercondylar notch: are they accurate? Arthroscopy 23: 261-268, 268 e261e262

2. Anderson AF, Lipscomb AB, Liudahl KJ, Addlestone RB (1987) Analysis of the intercondylar notch by computed tomography. Am J Sports Med 15:547-552

3. Brandon ML, Haynes PT, Bonamo JR, Flynn MI, Barrett GR, Sherman MF (2006) The association between posterior-inferior tibial slope and anterior cruciate ligament insufficiency. Arthroscopy 22:894-899

4. Charlton WP, St John TA, Ciccotti MG, Harrison N, Schweitzer M (2002) Differences in femoral notch anatomy between men and women: a magnetic resonance imaging study. Am J Sports Med 30:329-333

5. Chhabra A, Starman JS, Ferretti M, Vidal AF, Zantop T, Fu FH (2006) Anatomic, radiographic, biomechanical, and kinematic evaluation of the anterior cruciate ligament and its two functional bundles. J Bone Joint Surg Am 88(Suppl 4):2-10

6. Davis TJ, Shelbourne KD, Klootwyk TE (1999) Correlation of the intercondylar notch width of the femur to the width of the anterior and posterior cruciate ligaments. Knee Surg Sports Traumatol Arthrosc 7:209-214

7. Dejour H, Bonnin M (1994) Tibial translation after anterior cruciate ligament rupture. Two radiological tests compared. J Bone Joint Surg Br 76:745-749

8. Dienst M, Schneider G, Altmeyer K, Voelkering K, Georg T, Kramann B, Kohn D (2007) Correlation of intercondylar notch cross sections to the ACL size: a high resolution MR tomographic in vivo analysis. Arch Orthop Trauma Surg $127: 253-260$

9. Domzalski M, Grzelak P, Gabos P (2010) Risk factors for anterior cruciate ligament injury in skeletally immature patients: analysis of intercondylar notch width using magnetic resonance imaging. Int Orthop. doi:10.1007/s00264-010-0987-7

10. Gabriel MT, Wong EK, Woo SL, Yagi M, Debski RE (2004) Distribution of in situ forces in the anterior cruciate ligament in response to rotatory loads. J Orthop Res 22:85-89
11. Genin P, Weill G, Julliard R (1993) The tibial slope. Proposal for a measurement method. J Radiol 74:27-33

12. Giffin JR, Vogrin TM, Zantop T, Woo SL, Harner CD (2004) Effects of increasing tibial slope on the biomechanics of the knee. Am J Sports Med 32:376-382

13. Hashemi J, Chandrashekar N, Gill B, Beynnon BD, Slauterbeck JR, Schutt RC Jr, Mansouri H, Dabezies E (2008) The geometry of the tibial plateau and its influence on the biomechanics of the tibiofemoral joint. J Bone Joint Surg Am 90:2724-2734

14. Hashemi J, Chandrashekar N, Mansouri H, Gill B, Slauterbeck JR, Schutt RC Jr, Dabezies E, Beynnon BD (2010) Shallow medial tibial plateau and steep medial and lateral tibial slopes: new risk factors for anterior cruciate ligament injuries. Am J Sports Med 38:54-62

15. Hernigou P, Garabedian JM (2002) Intercondylar notch width and the risk for anterior cruciate ligament rupture in the osteoarthritic knee: evaluation by plain radiography and CT scan. Knee 9:313-316

16. Herzog RJ, Silliman JF, Hutton K, Rodkey WG, Steadman JR (1994) Measurements of the intercondylar notch by plain film radiography and magnetic resonance imaging. Am J Sports Med 22:204-210

17. Houseworth SW, Mauro VJ, Mellon BA, Kieffer DA (1987) The intercondylar notch in acute tears of the anterior cruciate ligament: a computer graphics study. Am J Sports Med $15: 221-224$

18. Ireland ML, Ballantyne BT, Little K, McClay IS (2001) A radiographic analysis of the relationship between the size and shape of the intercondylar notch and anterior cruciate ligament injury. Knee Surg Sports Traumatol Arthrosc 9:200-205

19. LaPrade RF, Burnett QM, 2nd (1994) Femoral intercondylar notch stenosis and correlation to anterior cruciate ligament injuries. A prospective study. Am J Sports Med 22:198-202 Discussion 203

20. Lombardo S, Sethi PM, Starkey C (2005) Intercondylar notch stenosis is not a risk factor for anterior cruciate ligament tears in professional male basketball players: an 11-year prospective study. Am J Sports Med 33:29-34

21. Lund-Hanssen H, Gannon J, Engebretsen L, Holen KJ, Anda S, Vatten L (1994) Intercondylar notch width and the risk for anterior cruciate ligament rupture. A case-control study in 46 female handball players. Acta Orthop Scand 65:529-532

22. Murshed KA, Cicekcibasi AE, Karabacakoglu A, Seker M, Ziylan T (2005) Distal femur morphometry: a gender and bilateral comparative study using magnetic resonance imaging. Surg Radiol Anat 27:108-112

23. Norwood LA Jr, Cross MJ (1977) The intercondylar shelf and the anterior cruciate ligament. Am J Sports Med 5:171-176

24. Petersen W, Tillmann B (1999) Structure and vascularization of the cruciate ligaments of the human knee joint. Anat Embryol (Berl) 200:325-334

25. Simon RA, Everhart JS, Nagaraja HN, Chaudhari AM (2010) A case-control study of anterior cruciate ligament volume, tibial plateau slopes and intercondylar notch dimensions in ACLinjured knees. J Biomech. doi:S0021-9290(10)00142-9

26. Souryal TO, Freeman TR (1993) Intercondylar notch size and anterior cruciate ligament injuries in athletes. A prospective study. Am J Sports Med 21:535-539

27. Souryal TO, Moore HA, Evans JP (1988) Bilaterality in anterior cruciate ligament injuries: associated intercondylar notch stenosis. Am J Sports Med 16:449-454

28. Stijak L, Herzog RF, Schai P (2008) Is there an influence of the tibial slope of the lateral condyle on the ACL lesion? A casecontrol study. Knee Surg Sports Traumatol Arthrosc 16:112-117

29. Stijak L, Radonjic V, Nikolic V, Blagojevic Z, Aksic M, Filipovic B (2009) Correlation between the morphometric 
parameters of the anterior cruciate ligament and the intercondylar width: gender and age differences. Knee Surg Sports Traumatol Arthrosc 17:812-817

30. Tillman MD, Smith KR, Bauer JA, Cauraugh JH, Falsetti AB, Pattishall JL (2002) Differences in three intercondylar notch geometry indices between males and females: a cadaver study. Knee 9:41-46

31. van Eck CF, Martins CA, Lorenz SG, Fu FH, Smolinski P (2010) Assessment of correlation between knee notch width index and the three-dimensional notch volume. Knee Surg Sports Traumatol Arthrosc. doi:10.1007/s00167-010-1131-3. (Epub ahead of print) 32. van Eck CF, Martins CA, Vyas SM, Celentano U, van Dijk CN, Fu FH (2010) Femoral intercondylar notch shape and dimensions in ACL-injured patients. Knee Surg Sports Traumatol Arthrosc. doi:10.1007/s00167-010-1135-z (Epub ahead of print)

33. Zantop T, Petersen W, Sekiya JK, Musahl V, Fu FH (2006) Anterior cruciate ligament anatomy and function relating to anatomical reconstruction. Knee Surg Sports Traumatol Arthrosc 14:982-992 